\title{
International Congress of Clinical Anatomy, 24-27 June 2015, Rouen, France
}

\author{
Bruno Grignon ${ }^{1} \cdot$ Fabrice Duparc ${ }^{2}$
}

Received: 4 July 2015 / Accepted: 11 July 2015 / Published online: 29 July 2015

(C) Springer-Verlag France 2015

After twelve previous meetings subsequently held in Brussels, Munich, Innsbruck, Lille, Constanta, Montpellier, Graz, Palermo, Prague, Istanbul, Padova, and Lisbon, Rouen was the venue of the XIIIth Congress of European Association of Clinical Anatomy (EACA), as well as the third joint EACA-British Association of Clinical Anatomy (BACA), jointly with the Spanish Anatomical Society. The congress was organized by Professor Fabrice Duparc.

The official opening ceremony was preceded by a brief overview of the previous EACA meetings, a special session devoted to lymphatics, and a brilliant lecture given by Professor Peter Abrahams (Warwick, UK), entitled "Leonardo Da Vinci: A 15th century anatomist whose conceptual ideas anticipated 21st radiology".

Scientific sessions subsequently devoted to AbdomenPelvis, Locomotor System, Head and Neck, Thorax and Heart, Spine and Peripheral Nervous System, Central Nervous System, Techniques in Anatomy, Education in Anatomy were animated by exciting invited lectures, free presentations, as well as posters, carried out by a number of colleagues interested in Clinical Anatomy, coming not only from Europe and UK, but also from the whole world. The project of a PDF version of the papers that could be accessible on the EACA website is being studied.

Bruno Grignon

b.grignon@chu-nancy.fr

Fabrice Duparc

fabrice.duparc@univ-rouen.fr

1 Faculté de Médecine, Université de Lorraine, CHU Nancy, Nancy, France

2 Faculté de Médecine Pharmacie, CHU Rouen, Rouen, France
"Human shoulder architecture and subacromial impingement syndrome" was the topic of an interesting guest lecture given by Professor Jean-Luc Voisin (Rennes, France) and a wonderful lecture entitled "Face/off: building the anatomical evidences behind the clinical inset and further progresses in face transplantation", performed by Professor Benoit Lengelé (Louvain, Belgium), encompassed all anatomical, surgical, technical, but also ethical, human and emotional aspects of this outstanding procedure and received a standing ovation.

The last scientific session, dealing with Education in Anatomy, illustrated the large variety of conventional and less conventional tools that can be used in the field, including peer-teaching, anatomical models, comics, analogies and mnemonics, body painting, virtual dissection based on surface laser scanning, computer-assisted learning, and ultrasound-based research selective besides traditional methods.

After the scientific sessions, the nice city of Rouen offered the charms of its famous gothic cathedral, its medieval center, the shadows of the Vikings, Joan of Arc, and the Impressionists, and every evening, the "Cathedral of Light" light and sound show gave a last shine on the three-day Capital of Clinical Anatomy. 